OPEN ACCESS

Edited by:

Emmanouil Apostolidis,

Framingham State University,

United States

Reviewed by:

Juscelino Tovar,

Lund University, Sweden

Luis Arturo Bello-Perez,

National Polytechnic Institute, Mexico

*Correspondence:

Dil Thavarajah

dthavar@clemson.edu

Specialty section: This article was submitted to

Food Chemistry,

a section of the journal

Frontiers in Nutrition

Received: 19 December 2018

Accepted: 14 March 2019

Published: 03 April 2019

Citation:

Siva N, Thavarajah P, Kumar S and Thavarajah D (2019) Variability in Prebiotic Carbohydrates in Different

Market Classes of Chickpea,

Common Bean, and Lentil Collected

From the American Local Market.

Front. Nutr. 6:38.

doi: 10.3389/fnut.2019.00038

\section{Variability in Prebiotic Carbohydrates in Different Market Classes of Chickpea, Common Bean, and Lentil Collected From the American Local Market}

\author{
Niroshan Siva ${ }^{1}$, Pushparajah Thavarajah ${ }^{1}$, Shiv Kumar ${ }^{2}$ and Dil Thavarajah ${ }^{1 *}$ \\ ${ }^{1}$ Plant and Environmental Sciences, Poole Agricultural Center, Clemson University, Clemson, SC, United States, ${ }^{2}$ Biodiversity \\ and Integrated Gene Management Program, International Centre for Agricultural Research in the Dry Areas (ICARDA), \\ Rabat-Institute, Rabat, Morocco
}

Pulse crops such as lentil, common bean, and chickpea are rich in protein, low digestible carbohydrates, and range of micronutrients. The detailed information of low digestible carbohydrates also known as "prebiotic carbohydrate" profiles of commonly consumed pulse market classes and their impact on human health are yet to be studied. The objective of this study was to determine the profiles of prebiotic carbohydrates in two commonly consumed lentil market classes, seven common bean market classes, and two chickpea market classes. After removing fat and protein, total carbohydrates averaged 51/100 $\mathrm{g}$ for lentil, 53/100 $\mathrm{g}$ for common bean, and 54/100 $\mathrm{g}$ for chickpea. Among the portion of total carbohydrates, lentil showed 12/100 $\mathrm{g}$ of prebiotic carbohydrates (sugar alcohols, raffinose family oligosaccharides, fructooligosaccharides, hemicellulose, cellulose, and resistant starch), 15/100 $\mathrm{g}$ in common bean, and 12/100 g in chickpea. Prebiotic carbohydrate concentrations within the market classes for each crop were significantly different $(P<0.05)$. In conclusion, these three pulses are rich in prebiotic carbohydrates, and considering the variation in these concentrations in the present materials, it is possible to breed appropriate market classes of pulses with high levels of prebiotic carbohydrates.

Keywords: pulse crops, low digestible carbohydrates, prebiotic carbohydrates, resistant starch, amylose

\section{INTRODUCTION}

Carbohydrates are widely present in plants and animals and are used as an energy source to fulfill metabolic requirements (1). Carbohydrates are classified into three major groups, simple sugars, oligosaccharides, and polysaccharides or complex carbohydrates, based on their chemical structure. Complex carbohydrates have a degree of polymerization 10 or more than the simple and oligosaccharides. Prebiotic carbohydrates, a category of complex carbohydrates also known as low digestible carbohydrates, are defined as "a selectively fermented ingredient that allows specific changes, both in the composition and/or activity in the gastrointestinal microflora that confers benefits upon host well-being and health" $(2,3)$. A prebiotic carbohydrate is a specific colonic nutrient that acts as a biosynthetic precursor for human microbiota activity. Classification of a food as a 
prebiotic carbohydrate requires that the ingredient: (1) resists digestive processes in the upper part of the gastrointestinal tract, (2) is fermented by intestinal microbiota, and (3) selectively stimulates growth and activity of health-promoting bacteria (2). Simple carbohydrates are comprised of one sugar unit (monosaccharides) or two sugar units (disaccharides) that are easily digestible, whereas oligosaccharides have 3 to 10 sugar units and complex carbohydrates feature more than ten sugar units (polysaccharides) (4).

Complex carbohydrates provide prebiotic health benefits by modulating healthy gut bacteria (5). Whole grains are rich in prebiotic carbohydrates, but most food processing techniques remove prebiotic carbohydrates, especially in cereals, i.e., white bread and breakfast cereal, so consumption of such foods can lead to an increased risk of obesity and related non-communicable diseases (6). Pulse crops, such as lentil (Lens culinaris Medikus.), common bean (Phaseolus vulgaris L.), and chickpea (Cicer arietinum L.) are consumed as whole foods and require minimal or no processing, and therefore contain higher amounts of prebiotic carbohydrates than processed cereals and other grains (7-9). Diets rich in prebiotic carbohydrates change the gut microbial composition, lead to production of fatty acids (acetate, butyrate, and propionate), regulate intestinal movement, and prevent constipation (2). Additionally, such diets tend to increase mineral absorption and reduce obesity risk by regulating blood glucose and cholesterol levels (10). However, the current daily intake of prebiotic carbohydrates in Western populations is $<50 \%$ of the recommended daily allowance (RDA) (11), but can be increased by incorporating pulses in the diet.

The benefits of prebiotic carbohydrates are not limited to humans, but also extend to plant health by increasing stress tolerance to cold and drought. For example, leaf raffinose family oligosaccharides (RFOs) enhance drought (12), chilling $(13,14)$, and freezing tolerance in plants (15). Further, sugar alcohols (SAs; sorbitol and mannitol) increase tolerance to chilling (16), drought (17), and salinity $(18,19)$. RFOs and SAs act as osmolytes to maintain cell structure during drought and salt stress $(12,20)$ and as antioxidants to neutralize the reactive oxygen species that cause cell damage $(13,14,21)$. Further, SAs and RFOs act as signaling compounds for biotic stress caused by insects and pathogens $(22,23)$.

Current annual lentil, common bean, and chickpea production around the world is $\sim 6,12$, and 26 million tons, respectively (24). With climate change, future pulse crop production might be limited because of increased drought and temperatures. As such, developing climate resilient and nutritionally superior cultivars via plant breeding and selection is essential for future pulse crop improvement and global food security (25). A $100 \mathrm{~g}$ serving of lentil contains $1-2 \mathrm{~g}$ of SA,

\footnotetext{
Abbreviations: Abs, Absorbance; ANOVA, Analysis of variance; $\mathrm{C}_{\mathrm{f}}$, Concentration of filtrate; $\mathrm{C}_{\mathrm{s}}$, Concentration of sample; $\mathrm{ddH}_{2} \mathrm{O}$, Distilled and deionized water; FOS, Fructooligosaccharides; HPAE, High performance anion exchange chromatography; LMWC, Low molecular weight carbohydrates; LSD, Least significant difference; $m$, Mass of the sample; PAD, Pulsed amperometric detector; RDA, Recommended daily allowance; RFO, Raffinose family oligosaccharides; RS, Resistant starch; SA, Sugar alcohol; SS, Soluble starch; $\mathrm{V}$, Volume of sample.
}

5-6g of RFO, 0-1 g of fructooligosaccharides (FOS), and 2-8 g resistant starch (RS) (9). However, very limited information in terms of detailed profiles of prebiotic carbohydrates is available for other pulses, including chickpea and common bean. The objective of this study was to identify and quantify prebiotic carbohydrate profiles (simple sugars, SA, RFO, FOS, RS, cellulose, hemicellulose, amylose) in two lentil market classes (red and green), seven common bean market classes (small red, cranberry, great northern, light red kidney, black, navy, and pinto), and two chickpea market classes (desi and kabuli).

\section{MATERIALS AND METHODS}

\section{Materials}

Chemicals used for high performance anion exchange chromatography (HPAE) and enzymatic assays were purchased from Fisher Scientific (Asheville, NC, USA), Sigma-Aldrich (St. Louis, MO, USA), and VWR International (Satellite Blvd, Suwanee, GA, USA). Distilled and deionized water $\left(\mathrm{ddH}_{2} \mathrm{O}\right)$ with a resistance of $\geq 18.2 \mathrm{M} \Omega$ (NANO-pure Diamond, Barnstead, IA, USA) was used in these analyses.

\section{Lentil, Common Bean, and Chickpea Seeds}

Approximately $4 \mathrm{~kg}$ of five commercially available lentil seed samples from two market classes (red and green) were collected from the Northern Pulse Growers Association, ND, USA. The red market class included whole seed (with seed coat), dehulled (whole seed without seed coat), and dehulled split (split seed without seed coat) and the green market class included whole seed and dehulled split (Table 1). Samples $(\sim 2 \mathrm{~kg})$ of seven commercially available common bean market classes (small red, cranberry, great northern, light red kidney, black, navy, and pinto) grown in the USA were obtained from local grocery stores, and two chickpea market classes (desi and kabuli) were obtained from a commercial pulse distributor (AGT Foods, Bismarck, ND, USA) (Table 1). These different pulse seed sample were collected from regional pulse distributors and local market, therefore additional information on growing conditions, soil management, and variety information were not available.

Samples were cleaned by hand, homogenized, subsampled, and ground to a 1-mm particle size using a cyclone mill (CT 193 Cyclotec Sample Mill, FOSS North America, MN, USA). The treatment design was a completely randomized design with five lentil types, seven common bean types, and two chickpea types $(n=14)$ and three replicates $(n=3)$, for a total of $42(n=42)$.

\section{Fat and Protein Removal}

Ground seed samples were dried at $100-102^{\circ} \mathrm{C}$ for $3 \mathrm{~h}$. Fat was removed with hexane at $90^{\circ} \mathrm{C}$ for $2 \mathrm{~h}$ in an ANKOM extractor (XT15, Macedon, NY, USA). Defatted samples were treated with $0.2 \% \mathrm{NaOH}(1: 6 ; \mathrm{w} / \mathrm{v})$ in a water bath at $45^{\circ} \mathrm{C}$ for $90 \mathrm{~min}$ to remove protein $(26,27)$. Samples were then blended for $2 \mathrm{~min}$ and centrifuged at 3,000 x g (Fisher Scientific, Waltham, MA, USA) for $15 \mathrm{~min}$. The supernatant was discarded, and the top layer was removed. Ten $\mathrm{mL}$ of $\mathrm{ddH}_{2} \mathrm{O}$ were added, the solution was mixed and centrifuged, and the supernatant and top layer was removed. This process was repeated until the top yellow layer 
TABLE 1 | Description of pulse market classes used in this experiment.

\begin{tabular}{lllc}
\hline Type & Market class & Commercial form & $\begin{array}{c}\mathbf{1 , 0 0 0} \text { seed } \\
\text { weight (g) }\end{array}$ \\
\hline Lentil & Red & Whole (with seed coat) & 29 \\
& & Dehulled dehulled & 33 \\
& Green & Dehulled split & 16 \\
& & Whole (with seed coat) & 46 \\
Common bean & Small red & Wholled (with seed coat) & 315 \\
& Cranberry & Whole (with seed coat) & 569 \\
& Great northern & Whole (with seed coat) & 338 \\
& Light red kidney & Whole (with seed coat) & 593 \\
& Black & Whole (with seed coat) & 182 \\
& Navy & Whole (with seed coat) & 198 \\
Pinto & Whole (with seed coat) & 344 \\
Desi & Whole (with seed coat) & 228 \\
Kabuli & Whole (with seed coat) & 473 \\
\hline
\end{tabular}

no longer visible. The suspension was re-suspended with $10 \mathrm{~mL}$ of $\mathrm{ddH}_{2} \mathrm{O}$ and adjusted to a $\mathrm{pH}$ of $\sim 7$ with $50 \mathrm{mM} \mathrm{HCl}$ (27). Following centrifugation, samples were washed three times with $\mathrm{ddH}_{2} \mathrm{O}$ and air dried at $60^{\circ} \mathrm{C}$ overnight.

\section{Low Molecular Weight Carbohydrates (LMWC)}

Ground seed samples (500 mg) were weighed into $15-\mathrm{mL}$ polypropylene conical tubes. Ten $\mathrm{mL}$ of $\mathrm{ddH}_{2} \mathrm{O}$ were then added to the tubes, which were incubated for $1 \mathrm{~h}$ at $80^{\circ} \mathrm{C}$ as per Muir et al. (28). Samples were centrifuged at $3,000 \mathrm{x} \mathrm{g}$ for $10 \mathrm{~min}$. An aliquot $(1 \mathrm{~mL})$ of the supernatant was diluted with $9 \mathrm{~mL}$ of $\mathrm{ddH}_{2} \mathrm{O}$, and the diluted supernatant was filtered through a $13 \mathrm{~mm} \times 0.45 \mu \mathrm{m}$ nylon syringe filter (Fisher Scientific, Waltham, MA, USA) prior to HPAE analysis.

Low molecular weight carbohydrate concentrations (SA, RFO, and FOS) were measured using HPAE (Dionex, ICS5000, Sunnyvale, CA, USA) according to a previously published method (29). SA, RFO, and FOS were determined by running the mobile phases (A: $100 \mathrm{mM}$ sodium hydroxide/600 mM sodium acetate; B: $200 \mathrm{mM}$ sodium hydroxide; $\mathrm{C}$ : $\mathrm{ddH}_{2} \mathrm{O}$ ) at a flow rate of $1 \mathrm{~mL} / \mathrm{min}$ through a CarboPac PA1 column [250 $\times$ $4 \mathrm{~mm}$; Dionex, CA, USA] connected to a CarboPac PA1 guard column $(50 \times 4 \mathrm{~mm}$; Dionex, CA, USA). The total run time was $25 \mathrm{~min}$. Detection was carried out using a pulsed amperometric detector (PAD; ICS-5000, Thermo Scientific, Waltham, MA, USA) with a working gold electrode and a silver-silver chloride reference electrode at $2.0 \mu \mathrm{A}$. Sugar alcohols (sorbitol and mannitol), RFO (raffinose, stachyose, and verbascose), and FOS (kestose and nystose) were identified and quantified using pure standards (>99\%), and low molecular weight carbohydrate concentrations were detected within a linear range of 3$1,000 \mu \mathrm{g} / \mathrm{g}$ with a minimum detection limit of $0.2 \mu \mathrm{g} / \mathrm{g}$. A lab reference (CDC Redberry lentil) was used to ensure the accuracy and reproducibility of detection. The peak areas of the external reference, glucose (100 ppm), SA (3-1,000 ppm), RFO (3-1,000 ppm), and FOS (3-1,000 ppm) were routinely analyzed for method consistency and detector sensitivity, with an error of $<5 \%$ (9). The concentration of LMWC in the samples $\left(C_{s}\right)$ was calculated according to $\mathrm{C}_{\mathrm{s}}=\left(\mathrm{C}_{\mathrm{f}} \times \mathrm{V}\right) / \mathrm{m}$, where $\mathrm{C}_{\mathrm{f}}$ is the filtrate concentration obtained from HPAE, $\mathrm{V}$ is the final diluted volume, and $\mathrm{m}$ is the mass of the sample (moisture corrected). Unidentified compound concentrations were determined based on of those identified carbohydrate peak areas that were very closest to retention times.

\section{Hemicellulose}

Samples weighing $500 \mathrm{mg}$ were loaded into $15-\mathrm{mL}$ polypropylene conical tubes, which were incubated with $5 \mathrm{~mL}$ of $7 \%(\mathrm{w} / \mathrm{w})$ $\mathrm{HCl}$ at $55^{\circ} \mathrm{C}$ for $120 \mathrm{~min}$ followed by centrifugation at 3,000 $\mathrm{x} g$ for $10 \mathrm{~min}$ (30). Concentrations of arabinose and xylose were measured using the HPAE-PAD method described above. Hemicellulose concentration was reported as the summation of arabinose and xylose concentrations, and then multiplied by 0.9 . Pectin concentration was not measured.

\section{Cellulose}

Cellulose was measured using enzymatic hydrolysis of cellulose (31). Cellulase enzyme (extracted from Aspergillus niger, $1 \mathrm{U}$ of enzyme liberates $1.0 \mu$ mole of glucose at $37^{\circ} \mathrm{C}$ for $1 \mathrm{~h}$ incubation) was purchased from Sigma-Aldrich, St. Louis, MO, USA. Samples $(100 \mathrm{mg})$ were weighed into $15-\mathrm{mL}$ polypropylene conical tubes. An aliquot $(3.5 \mathrm{~mL})$ of cellulase $(34 \mathrm{U} / \mathrm{mL}$ in $50 \mathrm{mM}$ citrate buffer, $\mathrm{pH}$ 4.7) was added and the mixture incubated in a water bath (Orbit shaker bath, Lab Line Instruments Inc., Melrose Park, ILL) with a rotary shaker $(200 \mathrm{rpm})$ at $37^{\circ} \mathrm{C}$ for $10 \mathrm{~h}$ (31). Tubes were then centrifuged at $3,000 \times \mathrm{g}$ for $10 \mathrm{~min}$ and $1 \mathrm{~mL}$ of the supernatant then diluted with $19 \mathrm{~mL}$ of $\mathrm{ddH}_{2} \mathrm{O}$. The total glucose concentration resulting from cellulose hydrolyzation was measured using an enzymatic assay (32). Aliquots $(0.1 \mathrm{~mL})$ of diluted solution and glucose standard (1 $\mathrm{mg} / \mathrm{mL}$ ) were added separately to $10-\mathrm{mL}$ round bottom glass tubes. Then, $3 \mathrm{~mL}$ of GOPOD reagent $(12,000 \mathrm{U} / \mathrm{L}$ glucose oxidase, $650 \mathrm{U} / \mathrm{L}$ peroxidase, and $0.4 \mathrm{mM} 4$-aminoantipyrine, $\mathrm{pH}$ 7.4) were added to each tube, which were then incubated in a water bath at $50^{\circ} \mathrm{C}$ for $20 \mathrm{~min}$. The absorption of the samples was measured using a spectrophotometer (Genesys 20, Thermo Scientific, NC, USA) at $510 \mathrm{~nm}$ (the absorbance value of the glucose standard) to determine the concentration of glucose in the samples. The cellulose concentration was determined by multiplying the glucose concentration by 0.9 (the ratio of free glucose to anhydro-glucose that occurs in cellulose).

\section{Resistant Starch}

RS concentrations were determined according to McCleary and Monaghan (33) and Megazyme (32). Ground samples (500 mg) were incubated with $4 \mathrm{~mL}$ of $100 \mathrm{mM}$ sodium malate $(\mathrm{pH} 6)$ containing $\alpha$-amylase $(10 \mathrm{mg} / \mathrm{mL})$ and amyloglucosidase (3 $\mathrm{U} / \mathrm{mL})$ for $16 \mathrm{~h}$ in a water bath $\left(37^{\circ} \mathrm{C}\right)$ with 200 strokes/min vertical shaking (Orbit shaker bath, Lab Line Instruments Inc., Melrose Park, IL, USA). After incubation, $4 \mathrm{~mL}$ of $95 \%$ ethanol were added, and the samples were then centrifuged at 1,500 $\mathrm{x} g$ 
for $10 \mathrm{~min}$ at room temperature. The pellets were re-suspended with $6 \mathrm{~mL}$ of ethanol ( $50 \% \mathrm{v} / \mathrm{v})$, centrifuged, and decanted. The resuspension and centrifugation process were done two times. Supernatants from the three centrifugations were pooled and brought to a volume of $100 \mathrm{~mL}$ with $\mathrm{ddH}_{2} \mathrm{O}$. The pellets were dissolved in $2 \mathrm{~mL}$ of potassium hydroxide $(2 \mathrm{M})$ in an ice bath $\left(\sim 0^{\circ} \mathrm{C}\right)$ while stirring with a magnetic stirrer for $20 \mathrm{~min}$. The suspensions were diluted with $8 \mathrm{~mL}$ of sodium acetate buffer (1.2 M, pH 3.8), with $0.1 \mathrm{~mL}$ of $3,300 \mathrm{U} / \mathrm{mL}$ amyloglucosidase then immediately added followed by incubation at $50^{\circ} \mathrm{C}$ for $30 \mathrm{~min}$. The suspension was then centrifuged at $1,500 \mathrm{x} \mathrm{g}$ for $10 \mathrm{~min}$ at room temperature. Aliquots $(0.1 \mathrm{ml})$ of both the supernatant containing the RS fractions and the diluted washings containing the soluble starch (SS) fractions were transferred separately to $10-\mathrm{mL}$ glass tubes. A reagent blank was prepared using $0.1 \mathrm{~mL}$ sodium acetate buffer $(\mathrm{pH} 4.5)$. An aliquot $(3 \mathrm{~mL})$ of GOPOD reagent was added to each tube, which were incubated in a water bath at $50^{\circ} \mathrm{C}$ for $20 \mathrm{~min}$. Absorption was measured using a spectrophotometer (Genesys 20, Thermo Scientific, NC, USA) at $510 \mathrm{~nm}$. Starch fractions were calculated as follows:

$$
\begin{aligned}
\mathrm{RS} & =\frac{\mathrm{X} \times\left(\mathrm{Abs}_{\text {sample }}\right)}{\left(\mathrm{Abs}_{\text {glucose }} \times \mathrm{W}_{\text {sample }}\right)}, \\
\mathrm{SS} & =\frac{\mathrm{Y} \times\left(\mathrm{Abs}_{\text {sample }}\right)}{\left(\mathrm{Abs}_{\text {glucose }} \times \mathrm{W}_{\text {sample }}\right)},
\end{aligned}
$$

where $\mathrm{Abs}_{\text {sample }}$ and $\mathrm{Abs}_{\text {glucose }}$ are the absorbance value of sample and glucose corrected against reagent blank, respectively; $\mathrm{W}_{\text {sample }}$ is the moisture corrected weight of sample; and $\mathrm{X}$ and $\mathrm{Y}$ are the dilutions factors for RS and SS, respectively. Regular corn starch [RS concentration $1.0 \pm 0.1 \%(\mathrm{w} / \mathrm{w})$ ] was used to verify the data, and batches were checked regularly to ensure an analytical error of $<10 \%$.

\section{Amylose and Amylopectin}

Amylose levels were determined using an enzymatic assay (34, 35). Samples (20-25 mg) of defatted and deproteinated flour were transferred to $15-\mathrm{mL}$ screw capped polypropylene conical tubes. An aliquot $(1 \mathrm{~mL})$ of dimethyl sulphoxide (DMSO; 99.5\% v/v) was added to each tube, which were heated for $1 \mathrm{~min}$ in a boiling water bath. The tube contents were then vigorously mixed in a high-speed vortex and heated for $15 \mathrm{~min}$ in a boiling water bath. The tubes were cooled to room temperature, and an aliquot $(2 \mathrm{~mL})$ of ethanol $(95 \% \mathrm{v} / \mathrm{v})$ added during continuous stirring. Then $4 \mathrm{~mL}$ of ethanol were added to the samples, which were allowed to stand for $15 \mathrm{~min}$ after thorough mixing. The tubes were centrifuged at 2,000 x g for $5 \mathrm{~min}$, and the supernatant discarded. Two $\mathrm{mL}$ of DMSO were added, and the samples heated for $15 \mathrm{~min}$ in a boiling water bath with occasional mixing. Immediately after their removal, $4 \mathrm{~mL}$ of concanavalin A (Con A) buffer (180 mM sodium acetate buffer, $\mathrm{pH}$ 6.4) were added to the samples, which were mixed thoroughly. The contents were diluted with Con A buffer to $25 \mathrm{~mL}$ (Solvent A).

Aliquots $(1 \mathrm{~mL})$ of diluted solvent A were transferred to 2$\mathrm{mL}$ microfuge tubes to which $0.5 \mathrm{~mL}$ of lectin Con A solution $(6 \mathrm{mg} / \mathrm{mL})$ was added. The tubes were mixed gently by repeated inversion and incubated for $1 \mathrm{~h}$ at room temperature followed by centrifugation at $14,000 \mathrm{x} \mathrm{g}$ for $10 \mathrm{~min}$. The supernatant $(1 \mathrm{~mL})$ was transferred to a $15-\mathrm{mL}$ centrifuge tube and $3 \mathrm{~mL}$ of sodium acetate buffer $(100 \mathrm{mM}, \mathrm{pH} 4.5)$ then added. The contents were mixed in a boiling water bath for $5 \mathrm{~min}$ and incubated at $40^{\circ} \mathrm{C}$ for $5 \mathrm{~min}$. Four $\mathrm{mL}$ of $100 \mathrm{mM}$ sodium acetate buffer were added to $0.5 \mathrm{~mL}$ of solvent A. An aliquot $(0.1 \mathrm{~mL})$ of amyloglucosidase $(333 \mathrm{U} / \mathrm{ml}) / \alpha$-amylase enzyme $(67 \mathrm{U} / \mathrm{mL})$ was added to the tubes containing either diluted solvent $\mathrm{A}$ or con A supernatant, which were then incubated at $40^{\circ} \mathrm{C}$ for $10 \mathrm{~min}$ followed by centrifugation at 2,000 x $\mathrm{g}$ for $5 \mathrm{~min}$. An aliquot $(4 \mathrm{~mL})$ of GOPOD reagent was added to $1 \mathrm{~mL}$ of supernatant and incubated at $40^{\circ} \mathrm{C}$ for $20 \mathrm{~min}$. Absorbance was measured at $510 \mathrm{~nm}$ in a spectrophotometer, with the percent amylose and amylopectin measured as follows:

$$
\begin{aligned}
\text { Amylose }(\%) & =\frac{\mathrm{Abs}_{(\text {Con A supernatant })}}{\mathrm{Abs}_{(\text {Total starch aliquot })}} \times \frac{6.15}{9.2} \times 100, \\
\text { Amylopectin }(\%) & =100 \%-\text { Amylose }(\%)
\end{aligned}
$$

\begin{tabular}{|c|c|c|c|}
\hline Carbohydrates & Lentil & Dry bean & Chickpea \\
\hline Sugar alcohols (mg/100 g) & $707 \pm 51$ & $11 \pm 3$ & $548 \pm 53$ \\
\hline \multicolumn{4}{|l|}{ Simple sugars } \\
\hline $\begin{array}{l}\text { Monosaccharides } \\
(\mathrm{mg} / 100 \mathrm{~g})\end{array}$ & $44 \pm 23$ & $66 \pm 15$ & $34 \pm 4$ \\
\hline Disaccharides (g/100 g) & $1.7 \pm 0.4$ & $3.1 \pm 0.4$ & $2.2 \pm 0.4$ \\
\hline \multicolumn{4}{|l|}{ Oligosaccharides } \\
\hline $\begin{array}{l}\text { Raffinose family } \\
\text { oligosaccharides (g/100 g) }\end{array}$ & $4.1 \pm 0.5$ & $3.0 \pm 0.3$ & $2.1 \pm 0.2$ \\
\hline $\begin{array}{l}\text { Fructooligosaccharides } \\
(\mathrm{mg} / 100 \mathrm{~g})\end{array}$ & $333 \pm 80$ & $52 \pm 13$ & $46 \pm 16$ \\
\hline \multicolumn{4}{|l|}{ Polysaccharides } \\
\hline Hemicellulose (g/100 g) & $3.8 \pm 0.2$ & $7.9 \pm 0.5$ & $6.1 \pm 0.5$ \\
\hline Cellulose (g/100 g) & $0.5 \pm 0.2$ & $1.6 \pm 0.9$ & $1.1 \pm 0.3$ \\
\hline Soluble starch (g/100 g) & $40 \pm 3$ & $41 \pm 3$ & $42 \pm 4$ \\
\hline Resistant starch (g/100 g) & $2.1 \pm 0.3$ & $2.4 \pm 0.4$ & $3.1 \pm 0.1$ \\
\hline Amylose (g/100 g) & $17 \pm 2$ & $19 \pm 2$ & $19 \pm 2$ \\
\hline Amylopectin (g/100 g) & $25 \pm 2$ & $24 \pm 2$ & $26 \pm 2$ \\
\hline $\begin{array}{l}\text { Unidentified Prebiotic } \\
\text { carbohydrates (mg/100 g) }\end{array}$ & $426 \pm 39$ & $151 \pm 28$ & $183 \pm 80$ \\
\hline $\begin{array}{l}\text { Total prebiotic } \\
\text { carbohydrates (g/100 g) }\end{array}$ & $12 \pm 1$ & $15 \pm 1$ & $12 \pm 2$ \\
\hline $\begin{array}{l}\text { Total identified } \\
\text { carbohydrates (g/100 g) }\end{array}$ & $51 \pm 2$ & $53 \pm 2$ & $54 \pm 7$ \\
\hline $\begin{array}{l}\text { RDA from a } 100 \mathrm{~g} \\
\text { serving (\%) }\end{array}$ & $60 \pm 6$ & $75 \pm 5$ & $60 \pm 8$ \\
\hline
\end{tabular}

where 6.15 and 9.2 are dilution factors for the Con A and total starch extracts, respectively.

TABLE 2 | Prebiotic carbohydrate profiles of lentil, common bean, and chickpea.

Data represent mean value \pm standard deviation. Values are presented on a wet weight basis (10\%). Recommendations for safe daily total prebiotic intake (20 g/day) reported by Douglas and Sanders (37). Unidentified compound concentrations were determined based on of those identified carbohydrate peak areas that were very closest to retention times. 


\section{Statistical Analysis}

Lentil, common bean, and chickpea market classes and replicates were considered as random factors and included as class variables. Analysis of variance (ANOVA) was performed using the General Linear Model procedure (PROC GLM) of SAS version 9.4 (36) and Fisher's protected least significant difference (LSD) at $P<0.05$ was used to separate means.

\section{RESULTS}

Total carbohydrate concentrations averaged 51/100 g in lentil, $53 / 100 \mathrm{~g}$ in common bean, and $54 / 100 \mathrm{~g}$ in chickpea, while total prebiotic carbohydrates averaged $12 / 100 \mathrm{~g}$ in lentil, $15 / 100 \mathrm{~g}$ in common bean, and $12 / 100 \mathrm{~g}$ in chickpea (Table 2). Sugar alcohols and oligosaccharide concentrations were generally higher in lentil whereas hemicellulose, cellulose, resistant starch, amylose, and amylopectin were slightly higher in common bean and chickpea.

\section{Lentil}

Among simple sugars, sucrose was the most abundant (1.17$2.289 / 100 \mathrm{~g})$ followed by glucose $(21-61 \mathrm{mg} / 100 \mathrm{~g})$, fructose $(0.2-$ $21.9 \mathrm{mg} / 100 \mathrm{~g})$, mannose $(1.2-7.9 \mathrm{mg} / 100 \mathrm{~g})$, and rhamnose (0.5-1.0 mg/100 g) (Table 3). For SAs, lentil contained higher concentrations of sorbitol $(606-733 \mathrm{mg} / 100 \mathrm{~g})$ than mannitol (9$31 \mathrm{mg} / 100 \mathrm{~g})$ and xylitol (14-31 mg/100 g) regardless of market class (Table 4$)$. Whole red had significantly $(P<0.05)$ higher levels of sorbitol than all other market classes, and whole green had significantly higher mannitol and xylitol concentrations. For RFO, stachyose concentrations (2.24-2.35/100 g) were higher than raffinose (403-646 $\mathrm{mg} / 100 \mathrm{~g})$ and verbascose (581-1,769 $\mathrm{mg} / 100 \mathrm{~g}$ ) concentrations (Table 5). Considering lentil FOS, concentrations of kestose were considerably higher than those for nystose. Arabinose concentrations were significantly higher in whole green compared to red split lentil (Figure 1A). Among the market classes, red dehulled, and red split had significantly higher xylose concentrations $(1,912-1,936 \mathrm{mg} / 100 \mathrm{~g})$ than the other market classes. Whole red and whole green had significantly higher cellulose concentrations (611-640 mg/100 g) than the other market classes (Figure 1A). Soluble starch concentrations ranged from 37 to $44 / 100 \mathrm{~g}$ with levels in red dehulled and dehulled green significantly higher than those in whole red and red split (Figure 2A). No significant differences were observed for RS levels among market classes; however, amylose concentrations were significantly higher in red dehulled, whole green, and dehulled green than in whole red (Figure 2A).

\section{Common Bean}

Among simple sugars, sucrose was the most abundant $(2,605-$ $3,710 \mathrm{mg} / 100 \mathrm{~g}$ ) followed by glucose (35-62 $\mathrm{mg} / 100 \mathrm{~g})$, fructose (1.7-16.4 mg/100 g), mannose (1.5-11.2 mg/100 g), and rhamnose $(0.1-0.7 \mathrm{mg} / 100 \mathrm{~g}$ ) (Table 3). Considering SAs, common beans had higher concentrations of mannitol (3-13 $\mathrm{mg} / 100 \mathrm{~g})$ than sorbitol $(0.1-2.3 \mathrm{mg} / 100 \mathrm{~g})$ and xylitol (1.9-8.6

TABLE 3 | Concentration of simple sugars of different lentil, common bean, and chickpea market classes.

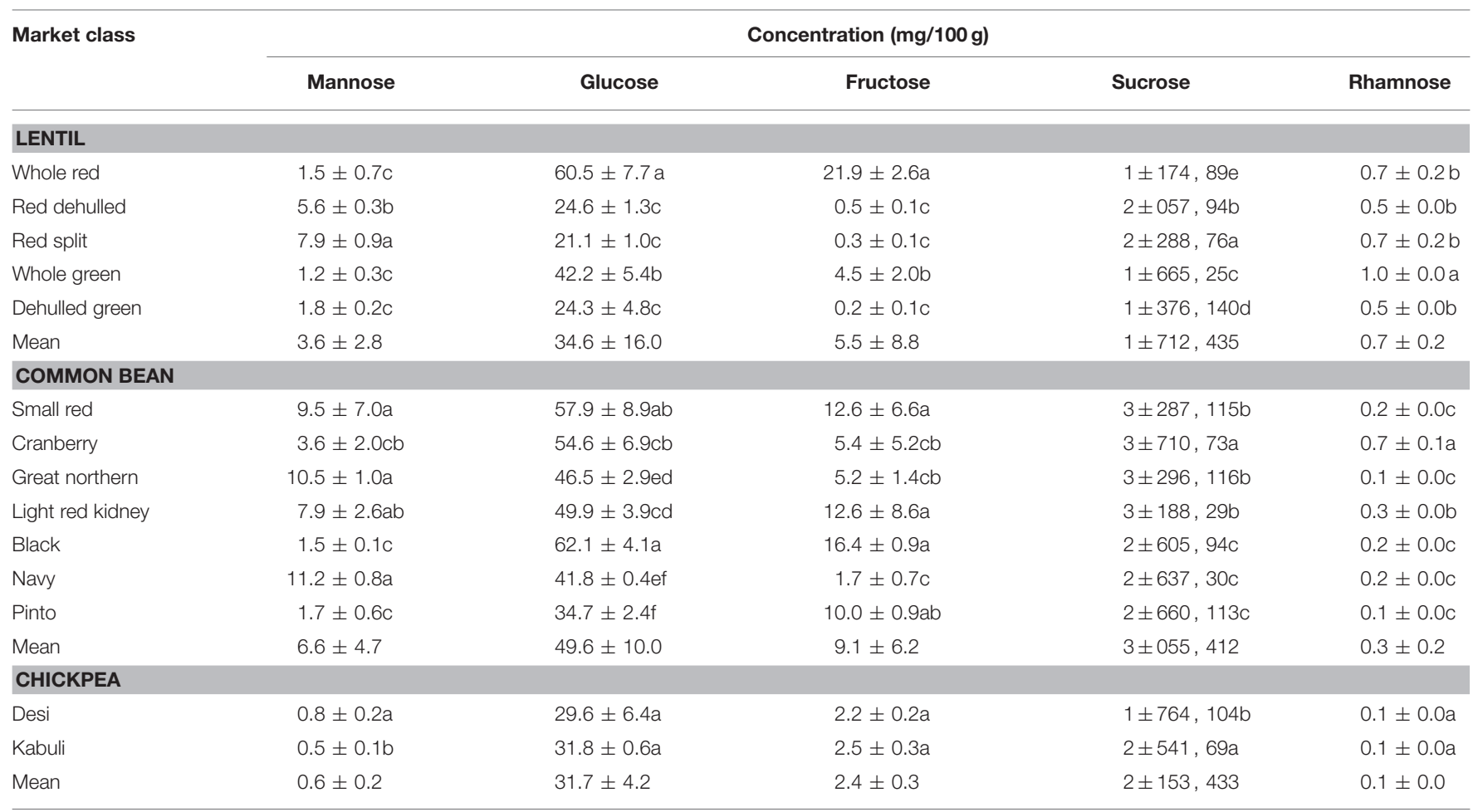

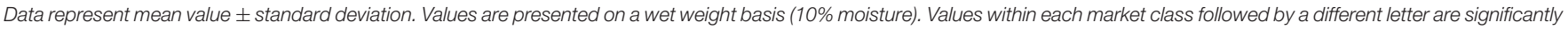
different at $P<0.05(n=42)$. 
TABLE 4 | Concentration of sugar alcohols (sorbitol, mannitol, and xylitol) of different lentil, common bean, and chickpea market classes.

\begin{tabular}{|c|c|c|c|}
\hline \multirow[t]{2}{*}{ Market class } & \multicolumn{3}{|c|}{ Concentration $(\mathrm{mg} / 100 \mathrm{~g})$} \\
\hline & Sorbitol & Mannitol & Xylitol \\
\hline \multicolumn{4}{|l|}{ LENTIL } \\
\hline Whole red & $733 \pm 44 a$ & $9 \pm 1 d$ & $14 \pm 1 d$ \\
\hline Red dehulled & $606 \pm 24 c$ & $21 \pm 1 c$ & $24 \pm 1 c$ \\
\hline Red split & $649 \pm 23 \mathrm{cb}$ & $22 \pm 4 c$ & $28 \pm 1 b$ \\
\hline Whole green & $631 \pm 7 \mathrm{cb}$ & $31 \pm 1 a$ & $31 \pm 1 a$ \\
\hline Dehulled green & $690 \pm 61 \mathrm{ab}$ & $27 \pm 4 b$ & $22 \pm 2 c$ \\
\hline Mean & $662 \pm 56$ & $22 \pm 8$ & $24 \pm 6$ \\
\hline \multicolumn{4}{|c|}{ COMMON BEAN } \\
\hline Small red & $0.8 \pm 0.0 c$ & $4.1 \pm 0.3 c$ & $3.8 \pm 0.1 \mathrm{c}$ \\
\hline Cranberry & $0.7 \pm 0.0 c$ & $8.8 \pm 0.6 b$ & $1.9 \pm 0.3 e$ \\
\hline Great northern & $0.2 \pm 0.0 e$ & $3.7 \pm 0.3 \mathrm{~cd}$ & $4.9 \pm 0.3 b$ \\
\hline Light red kidney & $0.1 \pm 0.1 e$ & $12.7 \pm 0.3 a$ & $3.1 \pm 0.1 d$ \\
\hline Black & $2.3 \pm 0.2 a$ & $3.1 \pm 0.1 \mathrm{ed}$ & $8.6 \pm 0.3 a$ \\
\hline Navy & $0.4 \pm 0.1 d$ & $3.0 \pm 0.4 \mathrm{e}$ & $3.5 \pm 0.4 \mathrm{~cd}$ \\
\hline Pinto & $1.2 \pm 0.2 b$ & $3.2 \pm 0.1 \mathrm{ed}$ & $3.7 \pm 0.4 c$ \\
\hline Mean & $0.8 \pm 0.7$ & $5.5 \pm 3.6$ & $4.2 \pm 2.0$ \\
\hline \multicolumn{4}{|l|}{ CHICKPEA } \\
\hline Desi & $557 \pm 16 a$ & $19 \pm 6 a$ & $18 \pm 1 a$ \\
\hline Kabuli & $473 \pm 8 b$ & $15 \pm 5 a$ & $14 \pm 0 b$ \\
\hline Mean & $515 \pm 48$ & $17 \pm 6$ & $16 \pm 2$ \\
\hline
\end{tabular}

Data represent mean value \pm standard deviation. Values are presented on a wet weight basis (10\% moisture). Values within each market class followed by a different letter are significantly different at $P<0.05(n=42)$.

$\mathrm{mg} / 100 \mathrm{~g}$ ) (Table 4). Among market classes, light red kidney bean had significantly $(P<0.05)$ higher mannitol concentrations and black bean had higher sorbitol and xylitol concentrations. Considering common bean RFO, stachyose concentrations were higher (1.77-2.49/100 g) than those for raffinose (532-754 $\mathrm{mg} / 100 \mathrm{~g}$ ) and verbascose $(128-187 \mathrm{mg} / 100 \mathrm{~g}$ ) (Table 5). For FOS, kestose concentrations (38-69 mg/100 g) were higher than nystose concentrations (0.01-0.01 mg/100 g) (Table 5). Common bean arabinose and xylose concentrations ranged from 5.3 to 6.6/100 g and 2.7-3.1/100 g, respectively (Figure 1B). Among common bean market classes, small red had significantly more $(P<0.05)$ arabinose and cranberry bean and light red kidney bean had significantly more $(P<0.05)$ xylose. Cellulose concentrations ranged from 0.9 to $3.4 / 100 \mathrm{~g}$, with navy bean having the highest concentration (Figure 1B). Soluble starch, RS, and amylose concentrations ranged from 38 to 44,2 to 3 , and 18 to $21 / 100$, respectively. Overall, cranberry bean had higher SS, RS, and amylose concentrations (Figure 2B).

\section{Chickpea}

Sucrose was the most abundant simple sugar (1.76-2.54/100 g) in chickpea, followed by glucose $(30-32 \mathrm{mg} / 100 \mathrm{~g})$, fructose $(2.2-2.5 \mathrm{mg} / 100 \mathrm{~g})$, mannose $(0.5-0.8 \mathrm{mg} / 100 \mathrm{~g})$, and rhamnose (0.1-0.1 mg/100 g) (Table 3). Among chickpea SAs, sorbitol concentrations (473-557 mg/100 g) were higher than mannitol $(15-19 \mathrm{mg} / 100 \mathrm{~g})$ and xylitol $(14-18 \mathrm{mg} / 100 \mathrm{~g})$ concentrations
(Table 4). Overall, desi had higher sorbitol, mannitol, and xylitol concentrations than kabuli; however, differences were only significant for sorbitol and xylitol $(P<0.05)$. Among RFO in chickpea, stachyose concentrations (1.44-1.63/100 g) were higher than raffinose (340-543 mg/100 g) and verbascose (127$113 \mathrm{mg} / 100 \mathrm{~g}$ ) concentrations (Table 5). Kabuli had significantly more $(P<0.05)$ raffinose and stachyose than desi. Considering FOS in chickpea, kestose concentration $(25-55 \mathrm{mg} / 100 \mathrm{~g})$ was higher than nystose concentration (2-9 mg/100 g) (Table 5). Arabinose, xylose, cellulose, SS, RS, and amylose concentrations ranged from 4.0 to $4.1,2.5$ to $3.0,0.9$ to $1.3,38$ to $45,3.1$ to 3.1 , and 17 to $21 / 100 \mathrm{~g}$, respectively, but none of these were significantly different between desi and kabuli (Figures 1C, 2C).

\section{DISCUSSION}

Pulses, including lentil, common bean, and chickpea, are traditional staple foods that have been consumed for several centuries because of their superior nutritional profile $(9,38-$ 40). However, increasing global demand for highly processed sugar and fat-rich foods has led to severe non-communicable disease epidemics, including obesity, overweight, and cancer (41). A diet rich in prebiotic carbohydrates, low in energy and glycemic response, moderate in protein, low in fat, and rich in micronutrients is now recommended for weight management (42). Cereal-based diets can satisfy daily caloric requirements, but do not provide daily requirements of prebiotic carbohydrates in a single serving (43). The present study indicates that pulses (lentil, common bean, and chickpea) provide $60-75 \%$ of the daily safe requirement of prebiotic carbohydrates ( $20 \mathrm{~g} /$ day) in a single serving [Table 2; (37)]. The official recommendations have not been made yet for prebiotic carbohydrate consumption, however several researches have offered suggestions for safe intake (37). Additionally, this current work provides information on the types and quantities of prebiotic carbohydrates in-different pulse market classes, which is valuable for further enhancement of nutritional via plant breeding and genetic selection.

Simple sugar concentrations in lentil, common bean, and chickpea are comparable to previous studies (44). Simple sugar concentrations in common bean were higher than in lentil and chickpea. In contrast, SA concentrations were higher in lentil and chickpea than in common bean. Simple sugars are precursors of SA formation in plants; however, this negative correlation between simple sugars and SA is largely dependent on plant type and weather conditions (45). Simply, from 5.1 to $6.7,1.7$ to 2.6, and 2.1 to $2.8 / 100 \mathrm{~g}$ for RFO (46-48) and 0.0 to $0.7,0.0$ to 0.5 , and 0.0 to $0.07 / 100 \mathrm{~g}$ for FOS $(49,50)$ in lentil, common bean, and chickpea, respectively; these values are comparable to those from the current study. Further, the present study found total polysaccharides are higher in common bean and chickpea than in lentil, similar to previous reports $(51,52)$. The composition of carbohydrates depends on their localization in the seed coat or cotyledon (8). Cell walls of the cotyledon contain a range of polysaccharides including cellulose, starch, and non-starchy noncellulosic glucans, while the seed coat contains large quantities of low molecular weight carbohydrates and cellulose but is low 
TABLE 5 | Raffinose family oligosaccharides (raffinose, stachyose, and verbascose) and fructooligosaccharides (kestose and nystose) concentrations in different lentil, common bean, and chickpea market classes.

\begin{tabular}{|c|c|c|c|c|c|}
\hline \multirow[t]{2}{*}{ Market class } & \multicolumn{3}{|c|}{ RFO (mg/100 g) } & \multicolumn{2}{|c|}{ FOS $(\mathrm{mg} / 100 \mathrm{~g})$} \\
\hline & Raffinose & Stachyose & Verbascose & Kestose & Nystose \\
\hline \multicolumn{6}{|l|}{ LENTIL } \\
\hline Whole red & $492 \pm 119 a b$ & $2294 \pm 35 a$ & $581 \pm 51 c$ & $191 \pm 16 b$ & $0.01 \pm 0.00 b$ \\
\hline Red dehulled & $464 \pm 32 \mathrm{ab}$ & $2236 \pm 107 a$ & $1435 \pm 74 b$ & $349 \pm 20 a$ & $0.01 \pm 0.00 b$ \\
\hline Red split & $646 \pm 144 a$ & $2348 \pm 198 a$ & $1769 \pm 43 a$ & $391 \pm 25 a$ & $0.01 \pm 0.00 b$ \\
\hline Whole green & $477 \pm 26 a b$ & $2290 \pm 71 a$ & $1653 \pm 68 \mathrm{a}$ & $382 \pm 2 a$ & $0.01 \pm 0.00 b$ \\
\hline Dehulled green & $403 \pm 96 b$ & $2292 \pm 66 a$ & $1333 \pm 153 b$ & $353 \pm 61 a$ & $0.08 \pm 0.04 a$ \\
\hline Mean & $496 \pm 116$ & $2292 \pm 100$ & $1354 \pm 437$ & $333 \pm 80$ & $0.02 \pm 0.03$ \\
\hline \multicolumn{6}{|c|}{ COMMON BEAN } \\
\hline Small red & $721 \pm 114 a$ & $2492 \pm 62 a$ & $128 \pm 31 b$ & $45 \pm 4 c b$ & $0.01 \pm 0.00 a$ \\
\hline Cranberry & $644 \pm 65 a b$ & $2436 \pm 70 a b$ & $187 \pm 16 a$ & $56 \pm 4 a b$ & $0.01 \pm 0.00 a$ \\
\hline Great northern & $626 \pm 47 a b$ & $2315 \pm 8 b$ & $157 \pm 21 a b$ & $43 \pm 6 c b$ & $0.01 \pm 0.00 a$ \\
\hline Light red kidney & $717 \pm 31 a$ & $2093 \pm 30 c$ & $181 \pm 16 a$ & $69 \pm 4 a$ & $0.01 \pm 0.00 a$ \\
\hline Black & $754 \pm 103 a$ & $2404 \pm 130 a b$ & $166 \pm 24 a b$ & $68 \pm 14 a$ & $0.01 \pm 0.00 a$ \\
\hline Navy & $642 \pm 31 a b$ & $2011 \pm 71 c$ & $187 \pm 31 a$ & $45 \pm 9 c b$ & $0.01 \pm 0.00 a$ \\
\hline Pinto & $532 \pm 52 b$ & $1774 \pm 41 d$ & $171 \pm 15 a b$ & $38 \pm 1 c$ & $0.01 \pm 0.00 a$ \\
\hline Mean & $662 \pm 93$ & $2218 \pm 258$ & $168 \pm 28$ & $52 \pm 13$ & $0.01 \pm 0.00$ \\
\hline \multicolumn{6}{|l|}{ CHICKPEA } \\
\hline Desi & $340 \pm 51 b$ & $1437 \pm 58 b$ & $113 \pm 24 a$ & $55 \pm 10 a$ & $2 \pm 2 a$ \\
\hline Kabuli & $543 \pm 48 a$ & $1629 \pm 6 a$ & $127 \pm 39 a$ & $25 \pm 6 a$ & $9 \pm 6 a$ \\
\hline Mean & $441 \pm 120$ & $1533 \pm 112$ & $120 \pm 30$ & $40 \pm 18$ & $5 \pm 6$ \\
\hline
\end{tabular}

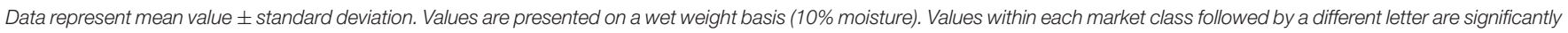
different at $P<0.05(n=42)$.

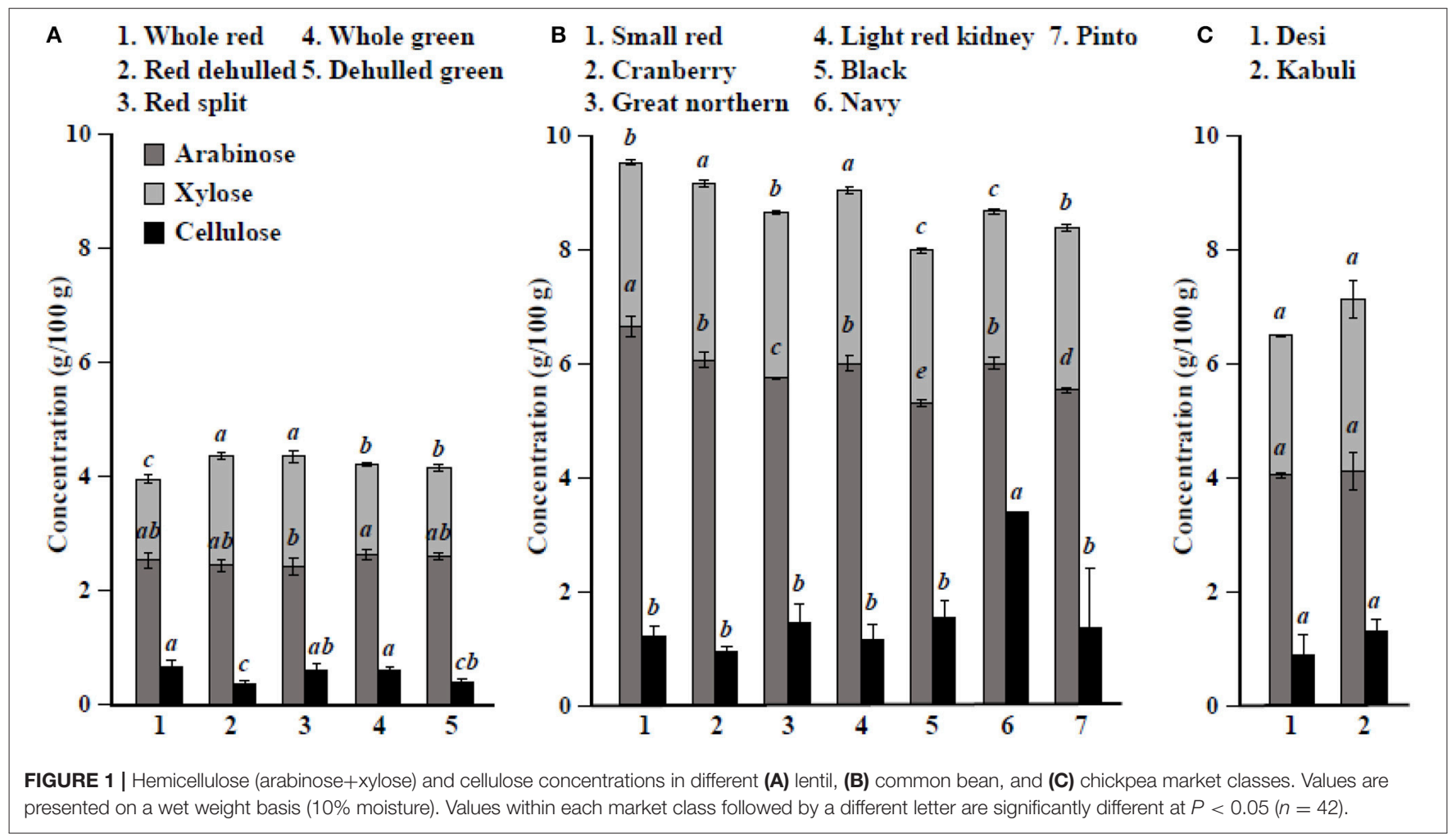




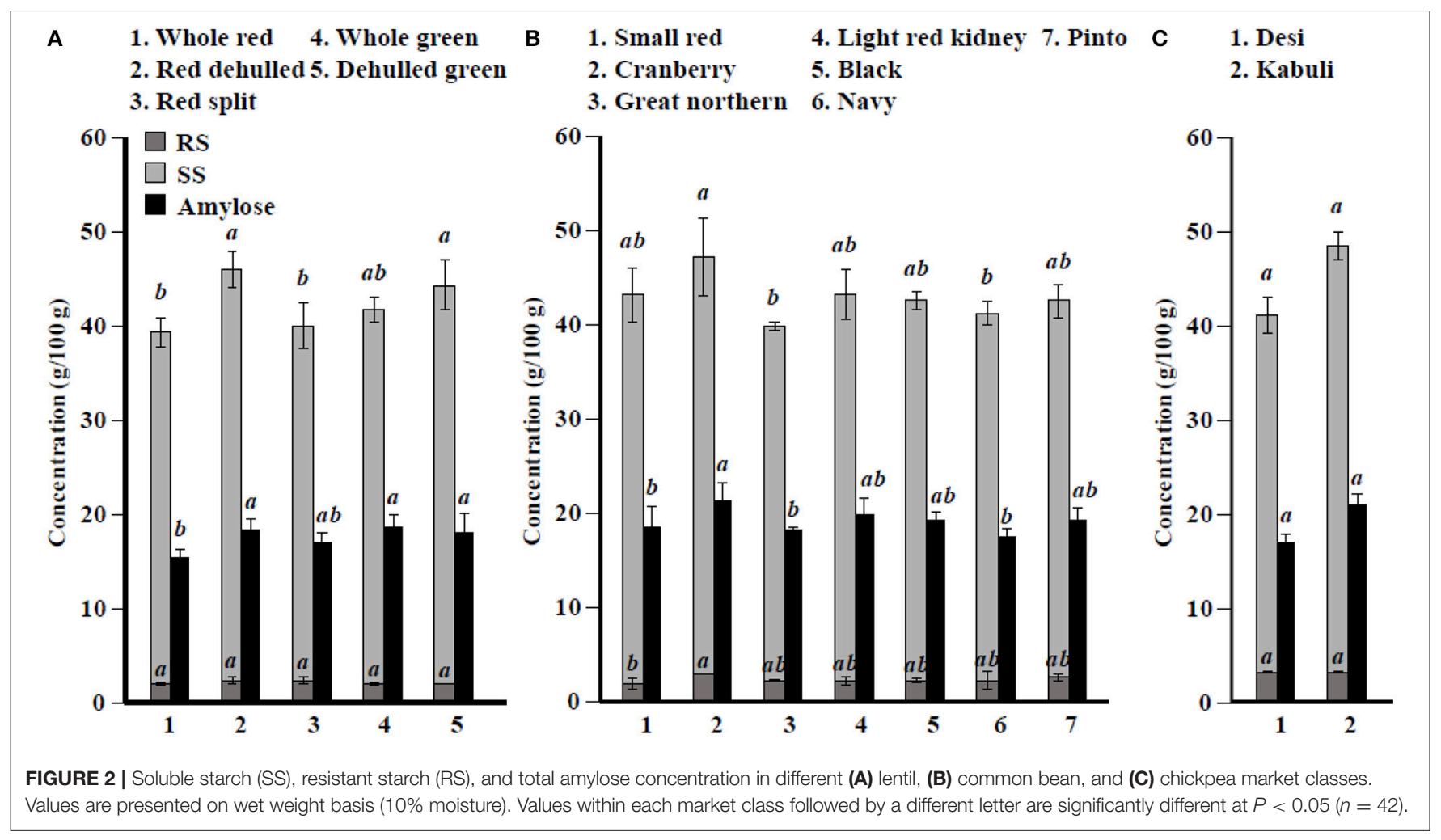

in hemicellulose (8). Lentil seeds are generally smaller than common bean and chickpea (Table 1); this might explain why increased levels of low molecular weight carbohydrates (SA, RFO, and FOS) are found in lentil while common bean and chickpea contain higher levels of cellulose and hemicellulose (Table 2).

Sucrose is the most abundant simple sugar found in pulses. During the development of the endosperm in the seed, the concentration of hexose declines while sucrose increases (53). Among lentil market classes, red lentil has higher levels of simple sugars than green lentil. Also, whole green lentil (lentil with seed coat) contains more sucrose, glucose, and fructose than dehulled green lentil, in accordance with earlier studies $(40,54)$ the opposite is true with respect to mannose (Table 3). In common bean, cranberry, small red, and great northern bean had higher total simple sugars while black and navy bean had the least (Table 3), showing significant variation among market classes due to structural (i.e., seed size), genetic, and environmental variations (48). Among chickpea market classes, kabuli had significantly more sucrose than desi due to its larger cotyledon size (55).

With respect to SAs, whole red lentil had higher sorbitol than dehulled lentil and dehulled red lentil had higher mannitol and xylitol; however, the opposite is true for green lentil, showing that SA distribution in lentil seed is influenced by both market class (red vs. green) and processing method (whole vs. dehulled), as noted previously (56). Common bean market classes also varied with respect to SA levels and had more mannitol and xylitol than sorbitol. Light red kidney bean, which has the largest seed size among studied market classes, had 50\% more SA than all other market classes. In chickpea, desi (smaller seed size, and hence more seed coat area) had more SA than kabuli, which is attributed to the more SA being present in seed coat than the cotyledon. Across all three pulse crop types, SA varied with seed size, market class, and processing method.

Lentil RFO concentration varies with genotype and growing environment $(9,50)$. Moreover, dehulling generally reduces raffinose concentrations but increases stachyose and verbascose concentrations $(40,47,56)$. In the current study, dehulling only increased verbascose concentration in red lentil. The greater variation in stachyose vs. raffinose and verbascose levels among common bean market classes might be due to genetic differences. Along with variations in seed size, seed coat thickness, and surface area, genetic makeup might affect the RFO concentration in common bean. In chickpea, more RFOs were found in kabuli (55), which has a large seed size and hence a larger seed cotyledon (Tables 1, 5). With respect to FOS, our data show higher levels of kestose present in the seed cotyledon than the seed coat in red lentil, with the reverse observed in green lentil (Table 5). Kestose levels varied significantly among common bean and chickpea market classes, indicating that kestose synthesis might be influenced by market class (57).

The seed coat contains most of the cellulose found in the seed (58). Our data confirm that whole lentil generally had higher cellulose levels than dehulled lentil. Similarly, arabinose and xylose were slightly higher in whole lentil and dehulled lentil, respectively, reflecting differences in the distribution of hemicellulose compounds in the seed. Cellulose levels are higher in common bean market classes when the seed size decreases, 
suggesting cellulose compounds are abundant in the seed coat. In contrast, arabinose and xylose levels are positively correlated with seed size. In chickpea, significant differences between desi and kabuli were not observed, which contrasts with previously reported results (52). Lentil dehulling slightly increases RS and SS as dehulling removes the starch-free seed coat, therefore concentrating starch fractions in the seed cotyledon $(47,56)$. In common bean and chickpea market classes, RS and SS are positively correlated with seed size (Figure 2B, Table 1), which relates to where starch compounds are stored in the cotyledon. Further, data from the current study confirm the positive correlation of amylose concentrations with RS, SS, and total starch (sum of RS and SS), similar to previous reports (59). Johnson et al. (47) indicated that significant changes in lentil RS concentration due to processing, cooking, and cooling. Cooling of cooked lentil increased RS concentration approximately twofold from $3.0 \%(\mathrm{w} / \mathrm{w})$ in cooked lentil to $5.5 \%(\mathrm{w} / \mathrm{w})$ after cooling. Further, RS concentrations ranged from 3 to $5 \%(\mathrm{w} / \mathrm{w})$ in raw lentil and the concentrations of RS in raw and cooked lentils were not significantly different (47). This current study reports only dry pulse seed RS concentrations for future breeding and selection purposes.

Overall, prebiotic carbohydrates represented 24, 28, and $22 \%$ of the total carbohydrate compounds in lentil, common bean, and chickpea, respectively. Prebiotic carbohydrate concentrations differ among pulses due to seed size, type of pulse, and processing method, and therefore incorporation of several pulses in the diet provides a range of different prebiotic carbohydrates needed for gut health. However, this present study did not report several prebiotic carbohydrates including pectin, and types of hemicellulose which does occur in most legume seeds. Further, complete profiling of carbohydrates in pulses provides useful information for future plant breeding and genetic studies to understand the prebiotic carbohydrate control mechanism in plants (60).

\section{REFERENCES}

1. Trumbo P, Schlicker S, Yates AA, Poos M. Dietary reference intakes for energy, carbohydrate, fiber, fat, fatty acids, cholesterol, protein and amino acids. J Am Diet Assoc. (2002) 102:1621-31. doi: 10.1016/S0002-8223(02)90346-9

2. Manning TS, Gibson GR. Prebiotics. Best Pract Res Clin Gastroenterol. (2004) 18:287-98. doi: 10.1016/j.bpg.2003.10.008

3. Hutkins RW, Krumbeck JA, Bindels LB, Cani PD, Fahey G, Goh YJ, et al. Prebiotics: why definitions matter. Curr Opin Biotechnol. (2016) 37:1-7. doi: 10.1016/J.COPBIO.2015.09.001.

4. Cummings JH, Stephen AM. Carbohydrate terminology and classification. Eur J Clin Nutr. (2007) 61:S5-18. doi: 10.1038/sj.ejcn.1602936

5. Oku T, Nakamura S. Comparison of digestibility and breath hydrogen gas excretion of fructo-oligosaccharide, galactosyl-sucrose and isomaltooligosaccharide in healthy human subjects. Eur J Clin Nutr. (2003) 57:1150-6. doi: $10.1038 /$ sj.ejcn. 1601666

6. Hodge AM, English DR, O'Dea K, Giles GG. Glycemic index and dietary fiber and the risk of type 2 diabetes. Diabetes Care. (2004) 27:2701-6. doi: $10.2337 /$ diacare.27.11.2701

7. Bhatty RS. Composition and quality of lentil (Lens culinaris Medik): a review. Can Inst Food Sci Technol J. (1988) 21:144-60. doi: 10.1016/S0315-5463(88)70770-1

\section{CONCLUSION}

This study shows the type and quantity of prebiotic carbohydrates varies with pulse crop, market class, seed size, and processing method. Lentil, common bean, and chickpea provide $60-75 \%$ of the suggested daily intake of prebiotic carbohydrates in a $100 \mathrm{~g}$ serving. Lentil is rich in low molecular weight carbohydrates including SA, RFO, and FOS, while common bean and chickpea are rich in polysaccharides such as cellulose, hemicellulose, and amylose. Overall, these pulses are rich in prebiotic carbohydrates, and further nutritional breeding is possible with identifying suitable growing locations, and genotypes producing higher levels of prebiotic carbohydrates in different pulse crop market classes.

\section{AUTHOR CONTRIBUTIONS}

NS: graduate student worked on the project - created all data, data analysis, and prepared first draft of this manuscript; PT: developed analytical assays, data analysis; SK: experimental design, manuscript editing; DT: PI of the project, graduate student supervision, data analysis, data interpretation, and manuscript writing and editing final version.

\section{FUNDING}

Funding support for this project was provided by the Plant Health and Production and Plant Products: Plant Breeding for Agricultural Production program area [grant no. 2018-6701427621 /project accession no. 1015284] of the USDA National Institute of Food and Agriculture, the International Center for Dry Land Agriculture (ICARDA, Morocco), and the American Pulse Association.

8. Guillon F, Champ MMJ. Carbohydrate fractions of legumes: uses in human nutrition and potential for health. Br J Nutr. (2002) 88:293. doi: 10.1079/bjn2002720

9. Johnson CR, Thavarajah D, Combs GF, Thavarajah P. Lentil (Lens culinaris L.): a prebiotic-rich whole food legume. Food Res Int. (2013) 51:107-13. doi: 10.1016/j.foodres.2012.11.025

10. Kaur N, Gupta A. Applications of inulin and oligofructose in health and nutrition. J Biosci. (2002) 27:703-14. doi: 10.1007/BF027 08379

11. Van Loo J, Coussement P, De Leenheer L, Hoebregs H, Smits G. On the presence of inulin and oligofructose as natural ingredients in the western diet. Crit Rev Food Sci Nutr. (1995) 35:525-52. doi: 10.1080/104083995095 27714

12. Bartels D, Sunkar R. Drought and salt tolerance in plants. CRC Crit Rev Plant Sci. (2005) 24:23-58. doi: 10.1080/073526805909 10410

13. Liu H, Dai X, Xu Y, Chong K. Over-expression of OsUGE-1 altered raffinose level and tolerance to abiotic stress but not morphology in Arabidopsis. J Plant Physiol. (2007) 164:1384-90. doi: 10.1016/j.jplph.2007.03.005

14. Nishizawa A, Yabuta Y, Shigeoka S. Galactinol and raffinose constitute a novel function to protect plants from oxidative damage. Plant Physiol. (2008) 147:1251-63. doi: 10.1104/pp.108.122465 
15. Pennycooke JC, Jones ML, Stushnoff C. Down-regulating alpha-galactosidase enhances freezing tolerance in transgenic petunia. Plant Physiol. (2003) 133:901-9. doi: 10.1104/pp.103.024554

16. Chiang Y, Stushnoff C, McSay A, Jones M, Bohnert H. Overexpression of mannitol-1-phosphate dehydrogenase increases mannitol accumulation and adds protection against chilling injury in petunia. J Am Soc Hortic Sci. (2005) 130:605-10. doi: 10.21273/JASHS.130.4.605

17. Pujni D, Chaudhary A, Rajam MV. Increased tolerance to salinity and drought in transgenic indica rice by mannitol accumulation. J Plant Biochem Biotechnol. (2007) 16:1-7. doi: 10.1007/BF033 21921

18. Tang W, Peng X, Newton RJ. Enhanced tolerance to salt stress in transgenic loblolly pine simultaneously expressing two genes encoding mannitol1-phosphate dehydrogenase and glucitol-6-phosphate dehydrogenase. Plant Physiol Biochem. (2005) 43:139-46. doi: 10.1016/j.plaphy.2005. 01.009

19. Zhifang G, Loescher WH. Expression of a celery mannose 6-phosphate reductase in Arabidopsis thaliana enhances salt tolerance and induces biosynthesis of both mannitol and a glucosyl-mannitol dimer. Plant Cell Environ. (2003) 26:275-83. doi: 10.1046/j.1365-3040.2003. 00958.x

20. Pharr D, Stoop J, Williamson J, Studer Feusi M, Massel M, Conkling M. The dual role of mannitol as osmoprotectant and photoassimilate in celery. HortScience. (1995) 30:1182-8.

21. Keunen E, Peshev D, Vangronsveld J, Van Den Ende W, Cuypers A. Plant sugars are crucial players in the oxidative challenge during abiotic stress: extending the traditional concept. Plant Cell Environ. (2013) 36:1242-55. doi: $10.1111 /$ pce. 12061

22. Kim MS, Cho SM, Kang EY, Im YJ, Hwangbo H, Kim YC, et al. Galactinol is a signaling component of the induced systemic resistance caused by Pseudomonas chlororaphis O6 root colonization. Mol Plant-Microbe Interact. (2008) 21:1643-53. doi: 10.1094/MPMI-21-12-1643

23. Valluru R, Van den Ende W. Myo-inositol and beyond Emerging networks under stress. Plant Sci. (2011) 181:387-400. doi: 10.1016/j.plantsci.2011.07.009

24. FAO. FAOSTAT. (2018). Available online at: http://faostat3.fao.org/home/E (Accessed May 20, 2018).

25. Muehlbauer FJ, Cho S, Sarker A, McPhee KE, Coyne CJ, Rajesh PN, et al. Application of biotechnology in breeding lentil for resistance to biotic and abiotic stress. Euphytica. (2006) 147:149-65. doi: 10.1007/s10681-006-7108-0

26. Neethirajan S, Tsukamoto K, Kanahara H, Sugiyama S. Ultrastructural analysis of buckwheat starch components using atomic force microscopy. $J$ Food Sci. (2012) 77:N2-7. doi: 10.1111/j.1750-3841.2011.02442.x

27. Sivapragasam N, Thavarajah P, Ohm JB, Thavarajah D. Enzyme resistant carbohydrate based micro-scale materials from sugar beet (Beta vulgaris L.) pulp for food and pharmaceutical applications. Bioact Carbohydrates Diet Fibre. (2014) 3:115-21. doi: 10.1016/j.bcdf.2014.03.004

28. Muir JG, Rose R, Rosella O, Liels K, Barrett JS, Shepherd SJ, et al. Measurement of short-chain carbohydrates in common Australian vegetables and fruits by high-performance liquid chromatography (HPLC). J Agric Food Chem. (2009) 57:554-65. doi: 10.1021/jf802700e

29. Feinberg M, San-Redon J, Assié A. Determination of complex polysaccharides by HPAE-PAD in foods: validation using accuracy profile. J Chromatogr $B$. (2009) 877:2388-95. doi: 10.1016/j.jchromb.2008.10.004

30. Thavarajah D, Thavarajah P, Abare A, Basnagala S, Lacher C, Smith P, et al. Mineral micronutrient and prebiotic carbohydrate profiles of USA-grown kale (Brassica oleracea L. var acephala) J Food Compos Anal. (2016) 52:9-15. doi: 10.1016/j.jfca.2016.07.003

31. Lee SH, Doherty TV, Linhardt RJ, Dordick JS. Ionic liquid-mediated selective extraction of lignin from wood leading to enhanced enzymatic cellulose hydrolysis. Biotechnol Bioeng. (2009) 102:1368-76. doi: 10.1002/bit.22179

32. Megazyme. Resistant Starch Assay Procedure. RSTAR 11/02. Megazyme Int. Ltd. Ireland (2012).

33. McCleary BV, Monaghan DA. Measurement of resistant starch. J AOAC Int. (2002) 85:665-75. doi: 10.1079/BJN19960178

34. Gibson TS, Solah VA, McCleary BV. A procedure to measure amylose in cereal starches and flours with concanavalin A. J Cereal Sci. (1997) 25:111-9. doi: $10.1006 /$ jcrs. 1996.0086
35. Megazyme. Amylose/Amylopectine Assay Procedure. K-AMYL 12/16. Megazyme International Ltd, Ireland (2016).

36. SAS. User's guide: Statistics SAS Institute, Version 9.4. Cary, NC: SAS Institute Inc. (2016).

37. Douglas L, Sanders M. Probiotics and prebiotics in dietetics practice. $J \quad A m$ Diet Assoc. (2008) 108:510-21. doi: 10.1016/j.jada.2007. 12.009

38. Sen Gupta D, Thavarajah D, Knutson P, Thavarajah P, McGee RJ, Coyne CJ, et al. Lentils (Lens culinaris L.), a rich source of folates. J Agric Food Chem. (2013) 61:7794-9. doi: 10.1021/jf401891p

39. Thavarajah D, Thavarajah P, Wejesuriya A, Rutzke M, Glahn RP, Combs $\mathrm{GF}$, et al. The potential of lentil (Lens culinaris L.) as a whole food for increased selenium, iron, and zinc intake: preliminary results from a 3 year study. Euphytica. (2011) 180:123-8. doi: 10.1007/s10681-0110365-6

40. Wang N, Hatcher DW, Toews R, Gawalko EJ. Influence of cooking and dehulling on nutritional composition of several varieties of lentils (Lens culinaris). LWT - Food Sci Technol. (2009) 42:842-8. doi: 10.1016/j.lwt.2008.10.007

41. Mitchell DC, Lawrence FR, Hartman TJ, Curran JM. Consumption of dry beans, peas, and lentils could improve diet quality in the US population. J Am Diet Assoc. (2009) 109:909-13. doi: 10.1016/j.jada.2009.02.029

42. WHO. Diet, Nutrition and the Prevention of Chronic Diseases. Report of the joint WHO/FAO expert consultation. WHO Technical Report Series, No 916 (TRS 916) (2014).

43. Williams CL. Importance of dietary fiber in childhood. J Am Diet Assoc. (1995) 95:1140-9. doi: 10.1016/S0002-8223(95)00307-X

44. Sánchez-Mata $M$, Peñuela-Teruel $M$, Cámara-Hurtado M, Díez-Marqués C, Torija-Isasa M. Determination of mono-, di-, and oligosaccharides in legumes by high-performance liquid chromatography using an aminobonded silica column. J Agric Food Chem. (1998) 46:3648-52. doi: 10.1021/jf98 $0127 \mathrm{w}$

45. Krasensky J, Jonak C. Drought, salt, and temperature stress-induced metabolic rearrangements and regulatory networks. J Exp Bot. (2012) 63:1593-608. doi: 10.1093/jxb/err460

46. Gangola MP, Jaiswal S, Kannan U, Gaur PM, Båga M, Chibbar, RN. Galactinol synthase enzyme activity influences raffinose family oligosaccharides (RFO) accumulation in developing chickpea (Cicer arietinum L.) seeds. Phytochemistry. (2016). 125:88-98. doi: 10.1016/j.phytochem.2016.02.009

47. Johnson CR, Thavarajah D, Thavarajah P, Payne S, Moore J, Ohm JB. Processing, cooking, and cooling affect prebiotic concentrations in lentil (Lens culinaris Medikus). J Food Compos Anal. (2015) 38:106-11. doi: 10.1016/j.jfca.2014.10.008

48. Reddy NR, Pierson MD, Sathe SK, Salunkhe DK. Chemical, nutritional and physiological aspects of dry bean carbohydrates - A review. Food Chem. (1984) 13:25-68. doi: 10.1016/0308-8146(84)90026-8

49. Biesiekierski JR, Rosella O, Rose R, Liels K, Barrett JS, Shepherd SJ, et al. Quantification of fructans, galacto-oligosacharides and other short-chain carbohydrates in processed grains and cereals. $J$ Hum Nutr Diet. (2011) 24:154-76. doi: 10.1111/j.1365-277X.2010. 01139.x

50. Johnson CR, Thavarajah D, Thavarajah P, Fenlason A, McGee R, Kumar S, et al. A global survey of low-molecular weight carbohydrates in lentils. J Food Compos Anal. (2015) 44:178-85. doi: 10.1016/j.jfca.2015.08.005

51. Dodevska MS, Djordjevic BI, Sobajic SS, Miletic ID, Djordjevic PB, Dimitrijevic-Sreckovic VS. Characterisation of dietary fibre components in cereals and legumes used in Serbian diet. Food Chem. (2013) 141:1624-9. doi: 10.1016/j.foodchem.2013.05.078

52. Singh U. Dietary fiber and its constituents in desi and kabuli chickpea (Cicer arietinum L.) cultivars. Nutr Rep Int. (1984) 29:419-26.

53. Hill LM, Morley-Smith ER, Rawsthorne S. Metabolism of sugars in the endosperm of developing seeds of oilseed rape. Plant Physiol. (2003) 131:22836. doi: $10.1104 /$ pp. 010868

54. Wang N. Effect of variety and crude protein content on dehulling quality and on the resulting chemical composition of red lentil (Lens culinaris). J Sci Food Agric. (2008) 88:885-90. doi: 10.1002/jsfa.3165

55. Wang N, Daun JK. The Chemical Composition and Nutritive Value of Canadian Pulses. Canadian Grain Commission Report (2004). 
56. Siva N, Thavarajah $\mathrm{P}$, Thavarajah $\mathrm{D}$. The impact of processing and cooking on prebiotic carbohydrates in lentil. J Food Compos Anal. (2018) 70:72-7. doi: 10.1016/j.jfca.2018.04.006

57. Patrick JW, Botha CF, Birch GR. Metabolic engineering of sugars and simple sugar derivatives in plants. Plant Biotechnol J. (2013) 11:142-56. doi: 10.1111/pbi. 12002

58. Bhattacharya S, Narasimha HV, Bhattacharya S. The moisture dependent physical and mechanical properties of whole lentil pulse and split cotyledon. Int J Food Sci Technol. (2005) 40:213-21. doi: 10.1111/j.1365-2621.2004. 00933.x

59. Yadav BS, Sharma A, Yadav RB. Studies on effect of multiple heating/cooling cycles on the resistant starch formation in cereals, legumes and tubers. Int J Food Sci Nutr. (2009) 60:258-72. doi: 10.1080/096374809029 70975
60. Vinocur B, Altman A. Recent advances in engineering plant tolerance to abiotic stress: achievements and limitations. Curr Opin Biotechnol. (2005) 16:123-32. doi: 10.1016/j.copbio.2005.02.001

Conflict of Interest Statement: The authors declare that the research was conducted in the absence of any commercial or financial relationships that could be construed as a potential conflict of interest.

Copyright (C) 2019 Siva, Thavarajah, Kumar and Thavarajah. This is an open-access article distributed under the terms of the Creative Commons Attribution License (CC $B Y)$. The use, distribution or reproduction in other forums is permitted, provided the original author(s) and the copyright owner(s) are credited and that the original publication in this journal is cited, in accordance with accepted academic practice. No use, distribution or reproduction is permitted which does not comply with these terms. 